\title{
Characterization of Secondary Metabolites Profile of Flavonoid from Salam Leaves (Eugenia polyantha) Using TLC and UV- Spectrophotometry
}

\author{
Anisa Lailatusy Syarifah ${ }^{1,2}$, Rurini Retnowati ${ }^{1 *}$, Soebiantoro ${ }^{1}$ \\ ${ }^{1}$ Department of Chemistry, Faculty of Mathematics and Natural Sciences, Brawijaya University, Malang, East Java, Indonesia \\ ${ }^{2}$ Academy of Pharmacy of Putra Indonesia Malang, Malang, East Java, Indonesia
}

\begin{tabular}{l} 
ARTICLE HISTORY \\
\hline Received: August 2019 \\
Revised: October 2019 \\
Accepted: November 2019
\end{tabular}

*Corresponding author

Email: rretnowati@ub.ac.id

\begin{abstract}
The flavonoids derived from Eugenia polyantha leaves were characterized by rapid and low cost approach. The aim of this research is to characterize secondary metabolite profile of flavonoids in the n-butanol fraction of E. polyantha using thin layer chromatography and ultraviolet-visible spectrophotometry. The n-butanol fraction was separated by using silica gel $60 \mathrm{GF}_{254}$ as the stationary phase; chloroform: ethanol: glacial acetic acid (9.4: $0.5: 0.1$ ) as the mobile phase; and visualized by using UV light $366 \mathrm{~nm}$. Five isolates were obtained from the separation, but there were only three isolates $\left(\mathrm{R}_{\mathrm{f}} 0.26 ; 0.44 ; 0.77\right)$ respectively identified as flavonoid compounds. The characterization of the isolates by UV-Vis spectrophotometry showing that the ranges of $\lambda_{\max }$ were $250-280 \mathrm{~nm}$ (band II) and 310-360 nm (band I), which indicate the existence of flavone compounds. Further characterization of the three isolate using the $\mathrm{AlCl}_{3} 5 \% / \mathrm{HCl} 6 \mathrm{M}$ solution showed that the $\lambda_{\max }$ shifted from band I to the higher wavelength (bathochromic). The $\lambda_{\text {max }}$ shift indicated the existences of ketone at C-4, hydroxyl group at $\mathrm{C}-5$, and orthodihydroxyl at ring $\mathrm{B}$. According to the maximum wavelength, the result of the characterization showed that the flavonoid compounds of the n-butanol were 5,3',4'-trihydroxyflavone3-C-glycoside or 5,4',5'-trihydroxyflavone-3-C-glycoside; 5,6,3',4'-tetrahydroxyflavone or $5,6,4^{\prime}, 5^{\prime}$-tetrahydroxyflavone; and 5,3',4'-trihydroxyflavone or 5,4',5'-trihydroxyflavone.
\end{abstract}

Keywords: Eugenia polyantha; flavon; flavonoid; thin layer chromatography; UV-Vis spectrophotometry

\section{INTRODUCTION}

Salam leaves (Eugenia polyantha), a member of the Myrtaceae family, can be used as spices and herbal medicine (Yuliani \& Nurdjannah, 2013). E. polyantha leaves contain tannin, flavonoid, and essential oil (Lelono, et al., 2009). The methanol extract of the $E$. polyantha bark has antioxidative activities $\left(\mathrm{ED}_{50}\right.$ $180 \mu \mathrm{g} / \mathrm{mL}$ ). The methanol extract was fractionated and the n-butanol, acetone, and ethyl acetate extracts exhibited antioxidative activities. Derivatization was conducted to the isolated antioxidative compounds prior to identification process. Then, rutin, a member of flavonoid compound, was isolated from the isolation process as active compound present in the Eugenia polyantha bark (Lelono and Tachibana, 2013). According to the research conducted by Ismail, et al. (2017) and Othman, et al. (2014), the extract of E. polyantha leaves is advantageous as an antioxidant because it contains of flavonoid. However, research about characterization of the secondary metabolite profile of flavonoids from $E$. polyantha leaves has not been conducted yet.

Thin Layer Chromatography (TLC) is frequently used to obtain and characterize flavonoid of the compounds that is present in herbal medicines. The TLC method can be used to analyze both the active compound in the plant and the quality of medicinal plant based on the harvesting time (Heryanto, et al., 2017). TLC using UV lamp detection and color reagents is widely used because it is a simple, low cost, and rapid method for qualitative analysis. But, TLC method must be combined with other methods to characterize flavonoid profile that is present in herbal medicines. Flavonoids have two specific spectrum, $\lambda_{\text {max }}$ in the range of 240-285 $\mathrm{nm}$ and 300-550 nm, therefore UV-Vis spectrophotometry can be used to characterize flavonoid compound. In this research, we have developed TLC analysis providing sufficient qualitative information of flavonoid. This TLC method, which will be combined with UV-Vis spectrophotometry, has several advantages, for example, it is fast, inexpensive, reliable, and simple to obtain specific qualitative analysis. These research are preliminary baseline data to get better development in TLC and UV-Vis spectrophotometry as the methods of profile characterization of flavonoid.

\section{METHODS}

\section{Chemicals}

Methanol (re-distilled) and silica gel $60 \mathrm{GF}_{254}$ TLC plates were used (Macherey-Nagel, Germany). All solvents and reagents used were analytical grade and obtained from Merck, such are n-hexane, ethyl acetate, diethyl ether, n-butanol, ethanol, chloroform, sulphuric acid 
97\%, magnesium powder, iodine, aluminum chloride, hydrochloric acid 37\%, magnesium sulfate anhydrate, glacial acetic acid, and benzene.

\section{Plants Materials}

Samples of Eugenia polyantha leaves were obtained and identified at UPT Materia Medica, Batu, East Java, Indonesia.

\section{Instruments}

TLC was carried out by using manual TLC system with flat bottom chamber while UV-Vis spectrophotometry was carried out using UV-Vis spectrophotometer 1601 Shimadzu.

\section{PROCEDURE}

\section{Extraction}

Fresh leaf samples were washed and dried in direct sunlight with fiberglass for 5 days. The dried leaves were sliced and pulverized resulting in simplicia powder. The simplicia powder samples of $300 \mathrm{~g}$ were macerated with methanol for 24 hours and afterward, the mixture was filtered before the powder was re-macerated with methanol for 24 hours. This procedure must be repeated until the colorless filtrate was obtained. The methanol extract was then concentrated using rotary evaporator vacuum to get a crude dried methanol extract.

\section{Fractionation of Methanol Extract by the Charaux- Paris Method}

The methanol extract was dissolved in hot water, stirred, and filtered using Buchner filter. The filtrate was extracted with n-hexane, diethyl ether, ethyl acetate, and n-butanol, respectively. After that, each filtrate was concentrated using rotary evaporator vacuum to obtain n-hexane extract, diethyl ether extract, ethyl acetate extract, and n-butanol extract.

The n-butanol fraction was evaluated for the presence of flavonoid compound using coloration reactions reported in standard reference books: The $2 \mathrm{~mL}$ of the $\mathrm{n}$-butanol fraction was put in the test tube, mixed with $2 \mathrm{~mL}$ of $\mathrm{HCl}$ $37 \%$ and 0.1 gram of $\mathrm{Mg}$ powder.

\section{Separation of Flavonoid Compounds by TLC using Different Solvent System}

n-Butanol fraction were tested in TLC for presence of flavonoids. The TLC pre-coated silica gel $60 \mathrm{GF}_{254}$ plates were developed using a flat bottom chamber which was pre-saturated with the mobile phase for 30 minutes and each plate was developed to a height of $6.0 \mathrm{~cm}$. In the TLC method, in order to obtain the effective isolation, the stationary phase and mobile phase's composition (eluent) must be optimized (Stahl \& Dumont, 1973). Therefore, the composition of mobile phase was optimized by using different mobile phase with various polarities. The various different mobile phases were ethyl acetate: methanol: water $(8.1: 1.1: 0.8)$; hexane: ethyl acetate $(1: 1),(7: 3),(8: 2),(9: 1)$; benzene: ethyl acetate (17:3), (19:1); and chloroform: ethanol: glacial acetic acid (8:1:1), (9:0.5:0.5), (9.4:0.5:0.1), (9.4:0.1:0.5). After development plates had been removed and dried, the spots were visualized in UV light (254 and $366 \mathrm{~nm}$ ) before being sprayed with $\mathrm{H}_{2} \mathrm{SO}_{4} 1 \%$ in methanol, and iodine vapor and calculated the value of its $\mathrm{R}_{\mathrm{f}^{\prime}}$ Once the brown spots were visualized when it was sprayed with the $\mathrm{H}_{2} \mathrm{SO}_{4} 1 \%$ in methanol and turn into yellow after being vapored with the iodine vapor, we could assume that the spots contains double bond compounds. On the other hand, if the spots were visualized with the UV 366 $\mathrm{nm}$, and resulting in blue, pink, or pale brown, we could assume that the spots contained flavonoids compounds.

\section{Preparative TLC}

n-Butanol fraction $1 \mathrm{~mL}$ were subjected to silica gel $60 \mathrm{GF}_{254}(16 \times 20 \mathrm{~cm})$ plate as the stationary phase and chloroform: ethanol: glacial acetic acid (9.4:0.1:0.5) as the mobile phases. The spots with the similar $\mathrm{R}_{\mathrm{f}}$ value were collected and dissolved in methanol. Furthermore, the supernatant was separated from the silica by the centrifuge. The obtained isolate was placed into the sample bottle and the methanol solvent was removed. Flavonoid compounds of each isolate were analyzed by UV spectrophotometry at 200-600 nm.

\section{Characterization of Flavonoid Compounds by UV- Vis Spectrophotometry}

Each isolate obtained from previous procedure $\left(\mathrm{R}_{\mathrm{f}} 0.1\right.$; $0.26 ; 0.44 ; 0.77 ; 0.86$ ) was placed into the cuvette before being analyzed using UV-Vis spectrophotometer at 200$600 \mathrm{~nm}$. Afterward, each isolate was added with $\mathrm{AlCl}_{3}$ $5 \%$ in methanol and $\mathrm{HCl} 6 \mathrm{M}$, then it was stirred until became homogenous. After that, it was analyzed using the UV-Vis spectrophotometer at 200-600 nm. When the isolate showed maximum wavelength at $240-285 \mathrm{~nm}$ and $300-550 \mathrm{~nm}$, it could be concluded that the isolate has flavonoid compounds. Furthermore, when the isolate showed maximum wavelength at 240-285 $\mathrm{nm}$ and 300$550 \mathrm{~nm}$ and more wavelength are shifted, it indicated the existence of hydroxyl group bond in the flavonoid compounds.

\section{RESULTS AND DISCUSSION}

\section{Fractionation of Methanol Extract by the Charaux- Paris Method}

In this research, the fractionation was conducted to isolate the main group of compounds from the others. The methanol extract fractionation with the CharauxParis method was conducted by using different solvents, as n-hexane, diethyl ether, ethyl acetate, and n-butanol, 


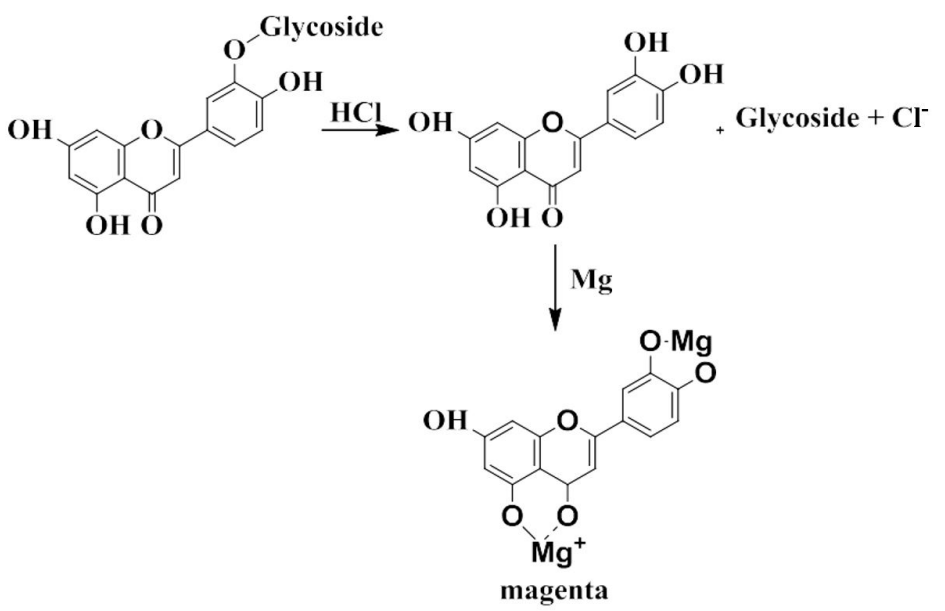

Figure 1. Flavonoid test by Wilstater Reaction (adapted from Markham, K.R., 1982)

depending on the polarity differences. Then, $15.22 \mathrm{~g}$ of n-hexane fraction, $15.05 \mathrm{~g}$ of diethyl-ether fraction, $15.75 \mathrm{~g}$ of ethyl acetate fraction, and $8.68 \mathrm{~g}$ of n-butanol fraction were produced. Prior to the fractionation, the methanol extract was dissolved in hot water to inhibit the enzyme activities. Enzyme lives at the optimum temperature of $25-37^{\circ} \mathrm{C}$ (Manitto, 1981). n-Hexane was used in the fractionation to extract and remove the resin and terpenoid, while diethyl ether was used to extract and remove the chlorophyll. According to the research conducted by Lelono \& Tachibana (2013), the n-butanol, acetone, and ethyl acetate extract exhibit the highest antioxidative activities. Therefore, in this research, n-butanol was used to characterize flavonoid profile.

\section{Flavonoid Test}

Flavonoid test was conducted according to the Wilstater reaction. The n-butanol fraction flavonoid test indicated that it positively contains flavonoid since the solution was turn into red or pink (magenta). The flavonoid reaction with $37 \% \mathrm{HCl}$ and magnesium powder is illustrated in Figure 1 (adapted from Markham, K.R., 1982). The Wilstater reaction was conducted to determine the existence of flavonoid compounds with $\gamma$-benzopyrone. The flavonoid test indicated the existence of flavonoid with $\gamma$-benzopyrone as flavone, flavonol, and isoflavone. In addition, the magenta discoloration indicated that the flavonoid had $\mathrm{C}=\mathrm{O}$ group at the $\mathrm{C}-4$ position and $-\mathrm{OH}$ group at C-5, C-3 position, and adjacent dihydroxyl at ring $\mathrm{B}$ (ortho position at 3' and 4' or 4' and 5').

\section{Isolation and Characterization of Flavonoid} Compounds of n-butanol Fraction by the TLC

Isolation and characterization of flavonoid compounds were performed with the TLC using silica gel $60 \mathrm{~F}_{254}$ as the stationary phase and some solvents as the mobile phase with various ratio composition shown in Table 1. Table 1 and the chromatogram show that the best mobile phase composition to isolate are chloroform: ethanol: glacial acetic acid $(9.4: 0.5: 0.1)$. It can be seen from the isolation result exhibiting the amount of spot and the result of the isolation in Figure 2 and 3.

Based on the polarity properties of each mobile phase, the mobile phase composition of ethyl acetate $(\varepsilon=$ $6.08)$ : methanol $(\varepsilon=33.0)$ : water $(\varepsilon=80.1)$ with the ratio of $(8.1: 1.1: 0.8)$ is the most polar. It is followed by the composition of chloroform $(\varepsilon=4.81)$ : ethanol ( $\varepsilon$ $=25.3)$ : glacial acetic acid $(\varepsilon=6.20)$ with the ratio of $(8: 1: 1)$ - $(9: 0.5: 0.5)-(9.4: 0.5: 0.1)-(9.4: 0.1: 0.5)$. The composition of benzene $(\varepsilon=2.28)$ : ethyl acetate with the ratio of (17:3) - (19:1) and the composition of n-hexane $(\varepsilon=1.89)$ : ethyl acetate with the ratio of $(1: 1)-(7: 3)-$ $(8: 2)$ - $(9: 1)$ respectively.

In this research, the characterization was performed using $1 \% \mathrm{H}_{2} \mathrm{SO}_{4}$ in methanol reagent, iodine vapor reagent, and UV light (254 and UV $366 \mathrm{~nm}$ ). The TLC chromatogram of the n-butanol fraction with $1 \% \mathrm{H}_{2} \mathrm{SO}_{4}$ in methanol is presented in Figure 2. There are 5 spots in which 4 spots were pale brown $\left(\mathrm{R}_{\mathrm{f}}(1) 0.19 ; \mathrm{R}_{\mathrm{f}}(3) 0.46 ; \mathrm{R}_{\mathrm{f}}(4) 0.77\right.$; $\left.R_{f}(5) 0.86\right)$ and the other spot was brown $\left(R_{f}(2) 0.28\right)$ indicating that each spot was hydrocarbon compound. Mechanism of the flavonoid oxidation reaction can be seen in Figure 4. This mechanism occured because the flavonoid was the hydrocarbon compounds.

The positive result of the iodine vapor test could support the flavonoid test result based on the Wilstater reaction exhibiting that the $n$-butanol fraction contains flavonoid compounds with $\gamma$ - benzopyrone ring (flavone, flavonol, and isoflavone). Three types of flavonoids have double bonds that can react with $\mathrm{I}_{2}$ so that the yellow discoloration occurs (Smith, 2011). The TLC chromatogram of the n-butanol fraction with iodine vapor is presented in Figure 3. The reaction occurred due to the $\mathrm{I}_{2}$ addition reaction to double bonds on flavonoid. The mechanism of $\mathrm{I}_{2}$ addition reaction to double bonds 
Table 1. $\mathbf{R}_{\mathrm{f}}$ value from TLC chromatograms

\begin{tabular}{|c|c|c|c|}
\hline No. & Mobile phase & Spot Amount & $\mathbf{R}_{\mathrm{f}}$ Value \\
\hline 1. & n-hexane : ethyl acetate $(1: 1)$ & 1 & $\mathrm{R}_{\mathrm{f} 1}=0.96$ \\
\hline 2. & n-hexane : ethyl acetate $(7: 3)$ & 1 & $\mathrm{R}_{\mathrm{f} 1}=0.97$ \\
\hline 3. & n-hexane : ethyl acetate $(8: 2)$ & 3 & $\begin{array}{l}\mathrm{R}_{\mathrm{f}}=0.75 \\
\mathrm{R}_{\mathrm{f} 2}=0.78 \\
\mathrm{R}_{\mathrm{f} 3}=0.83\end{array}$ \\
\hline 4. & n-hexane : ethyl acetate $(9: 1)$ & 2 & $\begin{array}{l}\mathrm{R}_{\mathrm{f}}=0.41 \\
\mathrm{R}_{\mathrm{f} 2}=0.49\end{array}$ \\
\hline 5. & benzene: ethyl acetate (17:3) & 4 & $\begin{array}{l}\mathrm{R}_{\mathrm{f} 1}=0.63 \\
\mathrm{R}_{\mathrm{f} 2}=0.67 \\
\mathrm{R}_{\mathrm{f} 3}=0.78 \\
\mathrm{R}_{\mathrm{f} 4}=0.82\end{array}$ \\
\hline 6. & benzene: ethyl acetate (19:1) & 2 & $\begin{array}{l}\mathrm{R}_{\mathrm{f} 1}=0.47 \\
\mathrm{R}_{\mathrm{f} 2}=0.51\end{array}$ \\
\hline 7. & $\begin{array}{l}\text { chloroform: ethanol: glacial acetic acid } \\
(8: 1: 1)\end{array}$ & 3 & $\begin{array}{l}\mathrm{R}_{\mathrm{f}}=0.12 \\
\mathrm{R}_{\mathrm{f} 2}=0.84 \\
\mathrm{R}_{\mathrm{f} 3}=0.96\end{array}$ \\
\hline 8. & $\begin{array}{l}\text { chloroform: ethanol: glacial acetic acid } \\
(9: 0.5: 0.5)\end{array}$ & 4 & $\begin{array}{l}\mathrm{R}_{\mathrm{f} 1}=0.15 \\
\mathrm{R}_{\mathrm{f} 2}=0.40 \\
\mathrm{R}_{\mathrm{f} 3}=0.82 \\
\mathrm{R}_{\mathrm{f} 4}=0.95\end{array}$ \\
\hline 9. & $\begin{array}{l}\text { chloroform: ethanol: glacial acetic acid } \\
(9.4: 0.5: 0.1)\end{array}$ & 5 & $\begin{array}{l}\mathrm{R}_{\mathrm{f}}=0.10 \\
\mathrm{R}_{\mathrm{f} 2}=0.26 \\
\mathrm{R}_{\mathrm{f} 3}=0.44 \\
\mathrm{R}_{\mathrm{f} 4}=0.77 \\
\mathrm{R}_{\mathrm{f} 5}=0.86\end{array}$ \\
\hline 10. & $\begin{array}{l}\text { chloroform: ethanol: glacial acetic acid } \\
(9.4: 0.1: 0.5)\end{array}$ & 3 & $\begin{array}{l}\mathrm{R}_{\mathrm{f}}=0.25 \\
\mathrm{R}_{\mathrm{f} 2}=0.42 \\
\mathrm{R}_{\mathrm{f} 3}=0.70\end{array}$ \\
\hline 11. & ethyl acetate:methanol:water $(8.1: 1.1: 0.8)$ & 4 & $\begin{array}{l}\mathrm{R}_{\mathrm{f} 1}=0.16 \\
\mathrm{R}_{\mathrm{f} 2}=0.25 \\
\mathrm{R}_{\mathrm{f} 3}=0.36 \\
\mathrm{R}_{\mathrm{f} 4}=0.82\end{array}$ \\
\hline
\end{tabular}

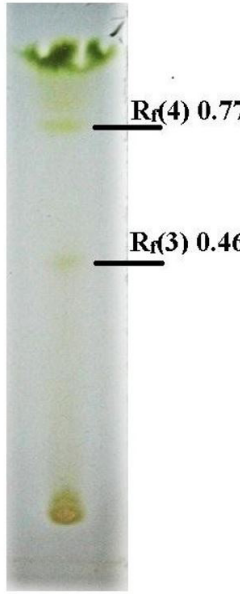

(a)

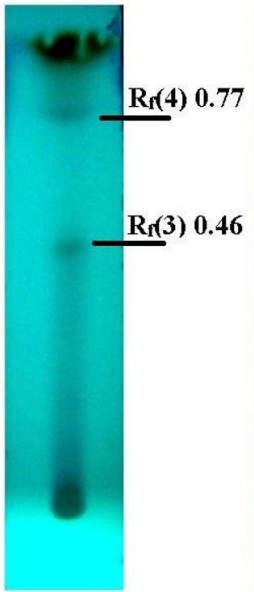

(b)

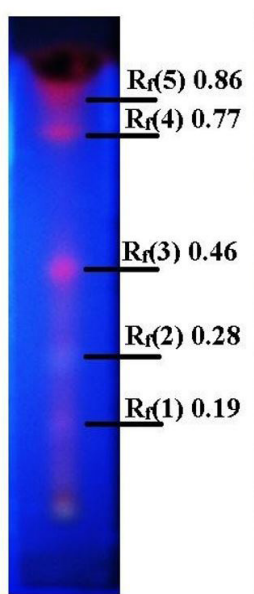

(c)

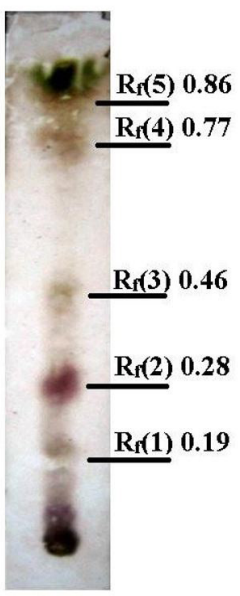

(d)

Figure 2. TLC chromatograms of n-butanol fraction from TLC using mobile phase (chloroform: ethanol: glacial acetic acid $(9.4: 0.5: 0.1, \mathrm{v} / \mathrm{v} / \mathrm{v})$ were observed by: (a) visible light, (b) UV $254 \mathrm{~nm}$, (c) UV $366 \mathrm{~nm}$, (d) with $\mathrm{H}_{2} \mathrm{SO}_{4} 1 \%$ in methanol reagent 


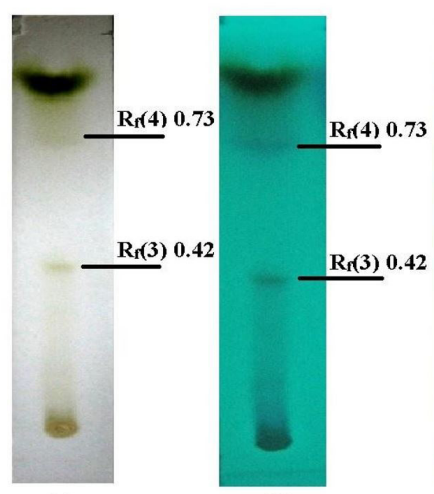

(a)

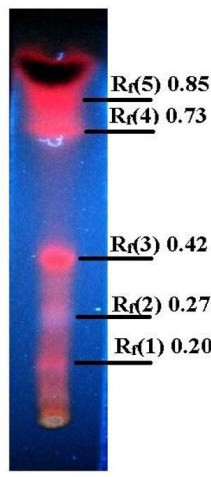

(c)

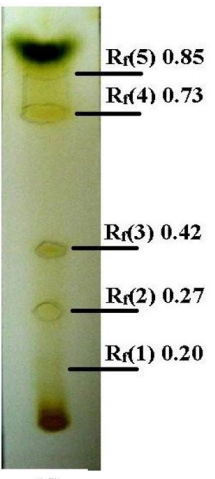

(d)

Figure 3. TLC chromatograms of n-butanol fraction from TLC using mobile phase (chloroform: ethanol: glacial acetic acid $(9.4: 0.5: 0.1, \mathrm{v} / \mathrm{v} / \mathrm{v})$ were observed by: (a) visible light, (b) UV $254 \mathrm{~nm}$, (c) UV $366 \mathrm{~nm}$, (d) with iodine vapor reagent<smiles>Cc1cc2oc(C3=CC(=O)C(=O)C=C3)c(O)c(=O)c2cc1OOc1ccc(Oc2ccc(-c3oc4ccccc4c(=O)c3O)cc2O)cc1</smiles>

Figure 4. Mechanism of the flavonoid oxidation reaction (adapted from Smith, 2011)<smiles>O=C1c2c(O)cccc2OC(Cl)(c2ccc(O)c(O)c2)C1I</smiles>

Figure 5. Mechanism of the $I_{2}$ addition reaction to double bonds on flavonoids (flavone) (Adapted from Smith, 2011)

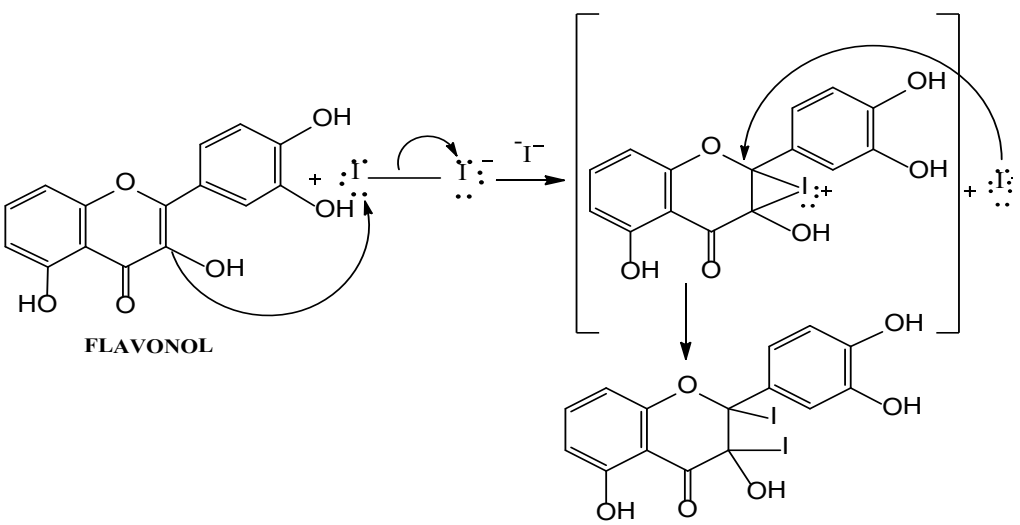

Figure 6. Mechanism of the $I_{2}$ addition reaction to double bonds on flavonoids (Flavonol) (Adapted from Smith, 2011) 
Table 2. Maximum wavelength of n-butanol fraction

\begin{tabular}{|c|c|c|c|}
\hline \multirow{2}{*}{ Isolate } & \multirow{2}{*}{$\mathbf{R}_{\mathrm{f}}$} & \multicolumn{2}{|r|}{$\lambda(\mathrm{nm})$} \\
\hline & & $\mathrm{MeOH}$ & $\mathrm{MeOH}+\mathrm{AlCl}_{3} / \mathrm{HCl}$ \\
\hline \multirow[t]{3}{*}{ I } & $\mathrm{R}_{\mathrm{f}}=0.10$ & 331.5 & 358.5 \\
\hline & & 215.0 & 215.0 \\
\hline & & - & 206.0 \\
\hline \multirow[t]{3}{*}{ II } & $\mathrm{R}_{\mathrm{f}}=0.26$ & 358.0 & 411.0 \\
\hline & & 265.0 & 270.0 \\
\hline & & 210.0 & 210.0 \\
\hline \multirow[t]{2}{*}{ III } & $\mathrm{R}_{\mathrm{f}}=0.44$ & 345.0 & 362.0 \\
\hline & & 266.0 & 272.0 \\
\hline \multirow[t]{3}{*}{ IV } & $\mathrm{R}_{\mathrm{f}}=0.77$ & 340.0 & 392.0 \\
\hline & & 264.0 & 272.0 \\
\hline & & 210.0 & 210.0 \\
\hline \multirow[t]{3}{*}{ V } & $\mathrm{R}_{\mathrm{f}}=0.86$ & - & 361.0 \\
\hline & & 315.5 & 313.5 \\
\hline & & 210.5 & 206.0 \\
\hline
\end{tabular}
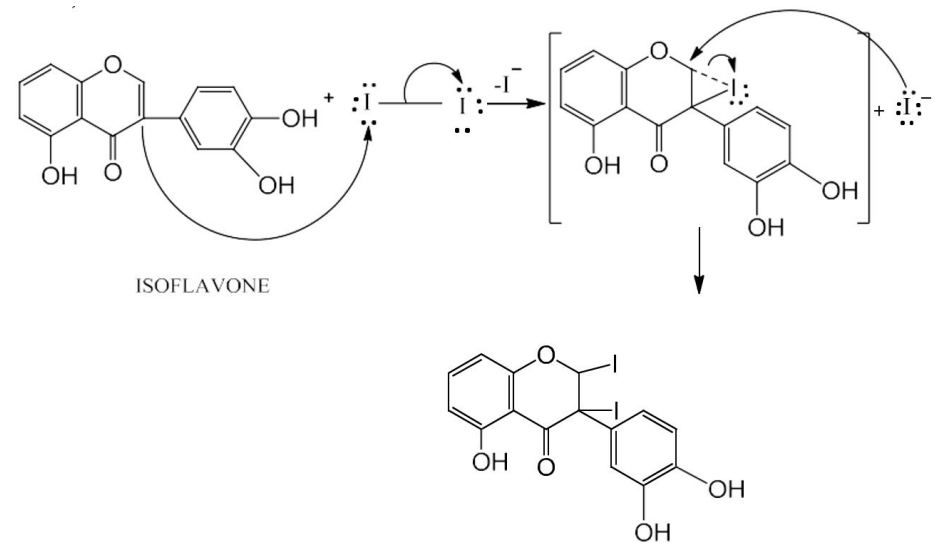

Figure 7. Mechanism of the $I_{2}$ addition reaction to double bonds on flavonoids (Isoflavone) (Adapted from Smith, 2011)

on flavonoids (flavone, flavonol, and isoflavone) are illustrated in Figure 5-7.

The TLC chromatogram of the n-butanol fraction with UV 254 and UV $366 \mathrm{~nm}$ are presented in Figure 2 and 3. There are 2 purple spots resulted in the TLC chromatogram with UV $254 \mathrm{~nm}\left(\mathrm{R}_{\mathrm{f}}\right.$ (3) 0.42; $\mathrm{R}_{\mathrm{f}}$ (4) $0.73)$; and 4 pink spots $\left(\mathrm{R}_{\mathrm{f}}(1) 0.20 ; \mathrm{R}_{\mathrm{f}}(3) 0.42 ; \mathrm{R}_{\mathrm{f}}(4)\right.$ $\left.0.73 ; \mathrm{R}_{\mathrm{f}}(5) 0.85\right)$. In addition, 1 blue spot $\left(\mathrm{R}_{\mathrm{f}}(2) 0.27\right)$ was resulted in the TLC chromatogram with UV 366 $\mathrm{nm}$. Blue and pink colors indicated that each spot has flavonoid.

Characterization of Flavonoid Compounds of n-butanol Fraction by the UV-Vis Spectrophotometry The UV-Vis spectrum in Table 2 indicates that isolate
II $\left(\mathrm{R}_{\mathrm{f}}(2) 0.26\right)$, III $\left(\mathrm{R}_{\mathrm{f}}(3) 0.44\right)$, and IV $\left(\mathrm{R}_{\mathrm{f}}(4) 0.77\right)$ were flavonoid compounds because they had two $\lambda_{\mathrm{m}}$ in the range of $240-285 \mathrm{~nm}$ and $300-550 \mathrm{~nm}$, included as flavonoid compounds specific spectrum. Then, the characterization using the UV-Vis spectrophotometry towards the three spots resulted in two $\lambda_{\max }$ of 250 $280 \mathrm{~nm}$ (band II) and 310-360 nm (band I) indicating the existence of flavone and flavonol with $3-\mathrm{OH}$ (substituted). Next, the characterization of the three isolates with $\mathrm{AlCl}_{3} 5 \% / \mathrm{HCl} 6 \mathrm{M}$ exhibited $\lambda_{\text {max }}$ shift of band I towards a longer wavelength (bathochromic). The $\lambda_{\max }$ shift indicated the existence of ketone group at C-4 and hydroxyl group at C-5, and orthodihydroxyl group at ring $\mathrm{B}$. Besides, the characterization of flavonoid was also based on the Woodward-Fieser rule. However, for a further investigation of flavonoid structure of n-butanol fraction, it should be identified using ${ }^{1} \mathrm{H}-\mathrm{NMR},{ }^{12} \mathrm{C}-\mathrm{NMR}$, 

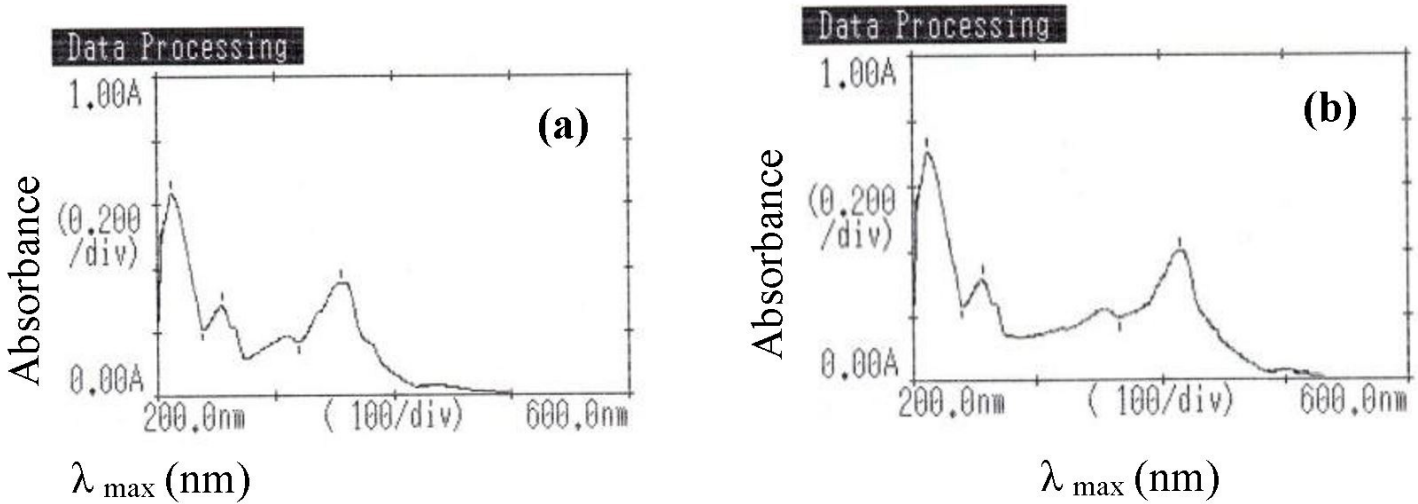

Figure 8. UV spectrum of isolate II (a). Isolate II; (b). Isolate $\mathrm{II}+\mathrm{AICl3} / \mathrm{HCl}$ reagent<smiles>Cc1c(-c2ccc(O)c(O)c2)oc2cccc(O)c2c1=O</smiles>

(a)<smiles>CCc1c(-c2ccc(O)c(O)c2)oc2cccc(O)c2c1=O</smiles>

(b)

Figure 9. Flavon structure:

(a) 5,3',4'-trihydroxyflavone-3-C-glycoside;(b) 5,4',5'-trihydroxyflavone-3-C-glycoside

HSQC, and HMBC. According to the UV-Vis spectrum data in Table 2, isolates II, III, and IV are characterized as in the following.

\section{Characterization of Flavonoid Compounds of Isolate II}

Isolate II had $\lambda_{\text {max }}$ at $265 \mathrm{~nm}$ (band II) and $358 \mathrm{~nm}$ (band I) (Figure 8.a) indicating flavonol with 3-OH (substituted). According to Hanani (2014), the substituents in flavonoid were $-\mathrm{OH},-\mathrm{OCH}_{3}, \mathrm{O}$-glycoside, and $\mathrm{C}$-glycoside. Flavonol 3-OH (substituted) had $\lambda_{\max }$ at $250-280 \mathrm{~nm}$ and 330-360 nm. The addition of $\mathrm{AlCl}_{3} / \mathrm{HCl}$ reagent caused the UV spectra to undergo the bathochromic shift of $53 \mathrm{~nm}$ (from $358 \mathrm{~nm}$ to $411 \mathrm{~nm}$ ) (Figure 8.b). It indicated the presence of $-\mathrm{OH}$ group at the $\mathrm{C}-5$ position. The bathochromic shift occurred because $\mathrm{AlCl}_{3}$ reacts with - $\mathrm{OH}$ group at the $\mathrm{C}-5$ position with $\mathrm{C}=\mathrm{O}$ group or $\mathrm{AlCl}_{3}$ reacts with dihydroxyl (ortho position at 3' and 4' or 4' and 5'). Besides, based on the Woodward-Fieser calculation, $\lambda_{\text {max }}$ of isolate II are $260 \mathrm{~nm}$ (band II) and $354 \mathrm{~nm}$ (band I); while in this research, $\lambda_{\max }$ were 265 (band II) and $358 \mathrm{~nm}$ (band I). The finding supported the existence of 3-OH (substituted) group with glycoside as the substituent. However, there was no significant $\lambda_{\max }$ shift in band II. It indicates the non-existence of ortho-dihydroxy at ring A $(6,7)$ or $(7,8)$. Therefore, the flavonoid compound in isolate II was more likely to be $5,3^{\prime}, 4^{\prime}$-trihydroxyflavone-3-C-glycoside or 5,4',5'-trihydroxyflavone-3-C-glycoside as in Figure 9.

\section{Characterization of Flavonoid Compounds of Isolate III}

Isolate III has $\lambda_{\text {max }}$ at $266 \mathrm{~nm}$ (band II) and $345 \mathrm{~nm}$ (band I) (Figure 10.a) indicating flavone. Flavone had $\lambda_{\text {max }}$ at 250-280 $\mathrm{nm}$ and 310-350 $\mathrm{nm}$. The addition of $\mathrm{AlCl}_{3} /$ $\mathrm{HCl}$ reagent caused the UV spectra to undergo the bathochromic shift of $17 \mathrm{~nm}$ (from $345 \mathrm{~nm}$ to $362 \mathrm{~nm}$ ) (Figure 10.b). It indicated the existence of -OH group at C-5 and C-6 position. The bathochromic shift occurred because $\mathrm{AlCl}_{3}$ reacted with -OH group at the $\mathrm{C}-5$ position with $\mathrm{C}=\mathrm{O}$ group or $\mathrm{AlCl}_{3}$ reacted with dihydroxyl (ortho position at 3' and 4' or 4' and 5'). Moreover, based on the Woodward-Fieser calculation, $\lambda_{\max }$ of isolate III are 267 $\mathrm{nm}$ (band II) and $344 \mathrm{~nm}$ (band I); while in this research, the $\lambda_{\text {max }}$ were 266 (band II) and $345 \mathrm{~nm}$ (band I). However, there was no significant $\lambda_{\text {max }}$ shift in band II. It indicated the non-existence of ortho-dihydroxy at ring $A(6,7)$ or $(7,8)$. Therefore, the flavonoid compound in isolate III 

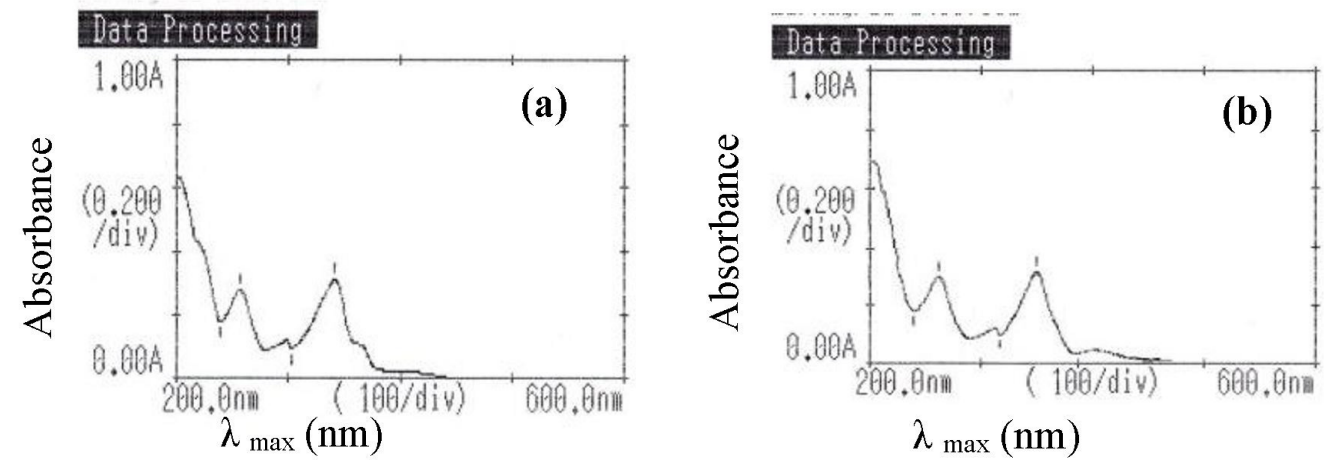

Figure 10. UV spectrum of isolate III

(a). Isolate III; (b). Isolate $\mathrm{III}+\mathrm{AlCl}_{3} / \mathrm{HCl}$ reagent<smiles></smiles>

(a)<smiles></smiles>

(b)

Figure 11. Flavon structure:

(a) 5,6,3',4'-tetrahydroxyflavone; (b) 5,6,4',5'-tetrahydroxyflavone
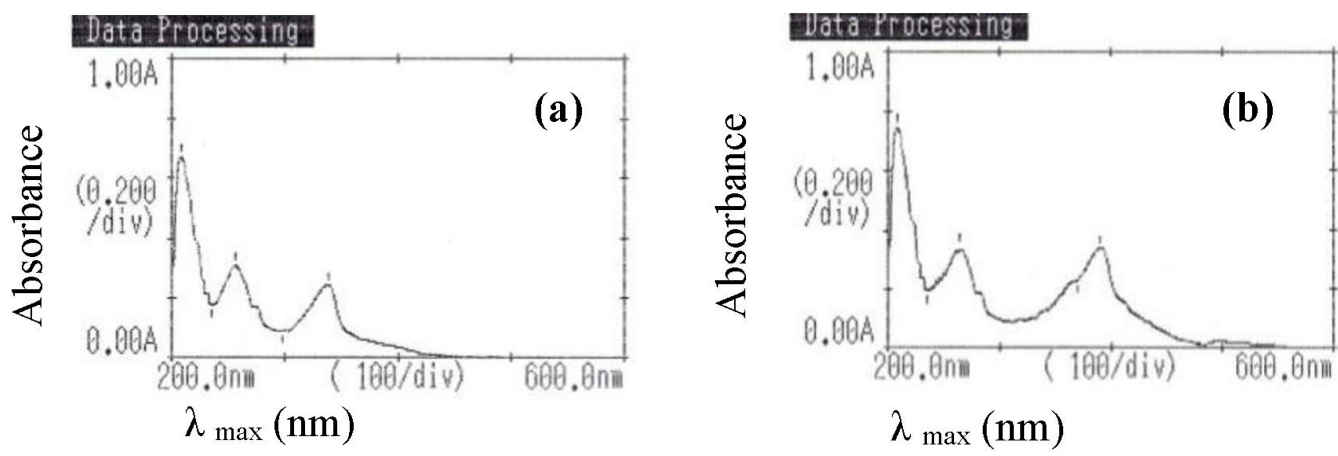

Figure 12. UV spectrum of isolate IV

(a). Isolate IV; (b). Isolate $\mathrm{IV}+\mathrm{AlCl}_{3} / \mathrm{HCl}$ reagent

was more likely to be $5,6,3^{\prime}, 4^{\prime}$ '-tetrahydroxyflavone or 5,6,4',5' - tetrahydroxyflavone as in Figure 11.

\section{Characterization of Flavonoid Compounds of Isolate IV}

Isolate IV had $\lambda_{\text {max }}$ at $264 \mathrm{~nm}$ (band II) and $340 \mathrm{~nm}$ (band I) (Figure 12.a) indicating flavone. Flavone had $\lambda_{\text {max }}$ at 250-280 $\mathrm{nm}$ and 310-350 nm. The addition of $\mathrm{AlCl}_{3}$ / $\mathrm{HCl}$ reagent caused the UV spectra to undergo the bathochromic shift of $52 \mathrm{~nm}$ (from $340 \mathrm{~nm}$ to $392 \mathrm{~nm}$ ) (Figure 12.b). It indicated the existence of -OH group at the C-5 position. The bathochromic shift occurred because $\mathrm{AlCl}_{3}$ reacted with -OH group at the $\mathrm{C}-5$ position with $\mathrm{C}=\mathrm{O}$ group or $\mathrm{AlCl}_{3}$ reacted with dihydroxyl (ortho position at 3' and 4' or 4' and 5'). Besides, based on the Woodward-Fieser calculation, $\lambda_{\max }$ of isolate IV are $260 \mathrm{~nm}$ (band II) and $344 \mathrm{~nm}$ (band I), while in this research, $\lambda_{\max }$ were 264 (band II) and $340 \mathrm{~nm}$ (band I). However, there is no significant $\lambda_{\max }$ shift in band II. It indicated the non-existence of ortho-dihydroxy at ring $\mathrm{A}$ $(6,7)$ or $(7,8)$. Therefore, flavonoid compound in isolate IV was more likely to be 5,3',4'-trihydroxyflavone or 5,4',5'-trihydroxyflavone as shown in Figure 13. 
<smiles>Cc1cccc2oc(-c3ccc(O)c(O)c3)cc(=O)c12</smiles>

(a)<smiles></smiles>

(b)

Figure 13. Flavon structure:

(a) 5,3',4'- trihydroxyflavone;(b) 5,4',5'- trihydroxyflavone

\section{CONCLUSION}

The isolation of n-butanol fraction indicated that the composition of chloroform: ethanol: glacial acetic acid (9.4:0.5:0.1) was the best mobile phase to isolate the flavonoid compounds. Based on the characterization result by the UV-Vis spectrophotometry, the flavonoid compounds in the n-butanol fraction were more likely to be 5,3',4'-trihydroxyflavone-3-C-glycoside or 5,4',5'-trihydroxyflavone-3-C-glycoside; 5,6,3',4' tetrahydroxyflavone or $5,6,4^{\prime}, 5^{\prime}$-tetrahydroxyflavone; and $5,3^{\prime}, 4^{\prime}$ '-trihydroxyflavone 5,4',5'-trihydroxyflavone.

\section{REFERENCES}

Hanani, E. (2014). Analisis Fitokimia. Jakarta. Penerbit EGC

Heryanto, R., Permana, D., Tedjo, A., Rohaeti, E., Rafi, M., \& Darusman, L. K. (2017). A Simple Photometer and Chemometrics Analysis for Quality Control of Sambiloto (Andrographis paniculata) Raw Material. The Journal of Pure and Applied Chemistry Research, $6(3), 238-245$

Ismail, H. F., Hashim, Z., Soon, W. T., Rahman, N. S. A., Zainudin, A. N., and Majid, F. A. A. (2017). Comparative study of herbal plants on the phenolic and flavonoid content, antioxidant activities and toxicity on cells and zebrafish embryo. Journal of Traditional and Complementary Medicine, 7(4), 452-465

Lelono, R.A., S. Tachibana and K. Itoh. (2009). In Vitro Antioxidative Activities and Polyphenol Content of Eugenia polyantha Wight Grown in Indonesia. Pakistan Journal of Biological Sciences, 12(24), 1564-1570.
Lelono, R. A., \& Tachibana, S. (2013). Bioassay-guided Isolation and Identification of Antioxidative Compounds from the Bark of Eugenia polyantha. Pakistan Journal of Biological Sciences, Vol. 16.

Manitto, P. (1981). Biosynthesis of Natural Products. Horwood Publisher. University of California

Markham, K. R. (1982). Techniques of Flavonoid Identification. Academic Press. The University of Michigan.

Othman, A., Mukhtar, N. J., Ismail, N. S., \& Chang, S. K. (2014). Phenolics, flavonoids content and antioxidant activities of 4 Malaysian herbal plants. International Food Research Journal, 21(2), 759-766

Smith, J. G. (2011). Organic Chemistry. Third Edition. New York: McGraw-Hill Companies. Inc.

Stahl, E. \& Dumont, E. (1973). Drug Analysis by Chromatography and Microscopy. Ann Arbor Science Publisher

Yuliani, S., \& Nurdjannah, N. (2013). Culinary powders and speciality products. In Handbook of Food Powders, 576-592, Elsevier 